\title{
Irreversible Electroporation and Nivolumab Combined with Intratumoral Administration of a Toll-Like Receptor Ligand, as a Means of In Vivo Vaccination for Metastatic Pancreatic Ductal Adenocarcinoma (PANFIRE-III). A Phase-I Study Protocol
}

\author{
Bart Geboers ${ }^{1, *}++^{(D}$, Florentine E. F. Timmer ${ }^{1,+} \mathbb{D}$, Alette H. Ruarus ${ }^{1}$, Johanna E. E. Pouw ${ }^{2} \mathbb{D}_{\text {, }}$ \\ Evelien A. C. Schouten ${ }^{1}$, Joyce Bakker ${ }^{2}$, Robbert S. Puijk ${ }^{1}{ }^{\mathbb{D}}$, Sanne Nieuwenhuizen ${ }^{1}$, Madelon Dijkstra ${ }^{1} \mathbb{D}$, \\ M. Petrousjka van den Tol ${ }^{3}$, Jan J. J. de Vries ${ }^{1}$, Daniela E. Oprea-Lager ${ }^{1}$, \\ C. Willemien Menke-van der Houven van Oordt ${ }^{2} \mathbb{D}$, Hans J. van der Vliet ${ }^{2,4}$, Johanna W. Wilmink ${ }^{2}$, \\ Hester J. Scheffer ${ }^{1}$, Tanja D. de Gruij1 ${ }^{2}$, Martijn R. Meijerink ${ }^{1}$ (D) \\ and on behalf of the Dutch Pancreatic Cancer Group $\ddagger$
}

1 Department of Radiology and Nuclear Medicine, Cancer Center Amsterdam, Amsterdam University Medical Centers, de Boelelaan 1117, 1081 HV Amsterdam, The Netherlands; f.timmer1@amsterdamumc.nl (F.E.F.T.); a.ruarus@amsterdamumc.nl (A.H.R.); e.schouten@amsterdamumc.nl (E.A.C.S.); r.puijk@amsterdamumc.nl (R.S.P.); s.nieuwenhuizen1@amsterdamumc.nl (S.N.); m.dijkstra3@amsterdamumc.nl (M.D.); j.devries1@amsterdamumc.nl (J.J.J.d.V.); d.oprea-lager@amsterdamumc.nl (D.E.O.-L.); hj.scheffer@amsterdamumc.nl (H.J.S.); mr.meijerink@amsterdamumc.nl (M.R.M.)

2 Department of Medical Oncology, Cancer Center Amsterdam, Amsterdam University Medical Centers, de Boelelaan 1117, 1081 HV Amsterdam, The Netherlands; j.e.e.pouw@amsterdamumc.nl (J.E.E.P.); j.bakker6@amsterdamumc.nl (J.B.); c.menke@amsterdamumc.nl (C.W.M.-v.d.H.v.O.); jj.vandervliet@amsterdamumc.nl (H.J.v.d.V.); j.w.wilmink@amsterdamumc.nl (J.W.W.); td.degruij1@amsterdamumc.nl (T.D.d.G.)

3 Department of Surgery, Amsterdam University Medical Centers, de Boelelaan 1117, 1081 HV Amsterdam, The Netherlands; mp.vandentol@amsterdamumc.nl

Citation: Geboers, B.; Timmer, F.E.F.; Ruarus, A.H.; Pouw, J.E.E.; Schouten, E.A.C.; Bakker, J.; Puijk, R.S.; Nieuwenhuizen, S.; Dijkstra, M.; van den Tol, M.P.; et al. Irreversible Electroporation and Nivolumab Combined with Intratumoral Administration of a Toll-Like Receptor Ligand, as a Means of In Vivo Vaccination for Metastatic Pancreatic Ductal Adenocarcinoma (PANFIRE-III). A Phase-I Study Protocol. Cancers 2021, 13, 3902. https://doi.org/10.3390/ cancers 13153902

Academic Editors: Sumit Sahni, Anubhav Mitta and Jaswinder Samra

4 Lava Therapeutics, Yalelaan 60, 3584 CM Utrecht, The Netherlands

* Correspondence: b.geboers@amsterdamumc.nl

+ Share first authorship.

$\ddagger \quad$ The Dutch Pancreatic Cancer Group are listed in acknowledgments.

Simple Summary: Metastatic pancreatic ductal adenocarcinoma has a dismal prognosis, and to date no curative treatment options exist. The image guided tumor ablation technique irreversible electroporation (IRE) employs high-voltage electrical pulses through the application of several needle electrodes in and around the tumor in order to induce cell death. IRE ablation of the primary tumor has the ability to reduce pancreatic tumor induced immune suppression while allowing the expansion of tumor specific effector T cells, hereby possibly shifting the pancreatic tumor microenvironment into a more immune permissive state. The addition of immune enhancing therapies to IRE might work synergistically and could potentially induce a clinically significant treatment effect. This study protocol describes the rationale and design of the PANFIRE-III trial that aims to assess the safety of the combination of IRE with IMO-2125 (toll-like receptor 9 ligand) and/or nivolumab in patients with metastatic pancreatic ductal adenocarcinoma.

Abstract: Irreversible electroporation (IRE) is a novel image-guided tumor ablation technique with the ability to generate a window for the establishment of systemic antitumor immunity. IRE transiently alters the tumor's immunosuppressive microenvironment while simultaneously generating antigen release, thereby instigating an adaptive immune response. Combining IRE with immunotherapeutic drugs, i.e., electroimmunotherapy, has synergistic potential and might induce a durable antitumor response. The primary objective of this study is to assess the safety of the combination of IRE with IMO-2125 (a toll-like receptor 9 ligand) and/or nivolumab in patients with metastatic pancreatic 
Publisher's Note: MDPI stays neutral with regard to jurisdictional claims in published maps and institutional affiliations.

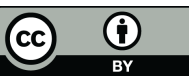

Copyright: (C) 2021 by the authors. Licensee MDPI, Basel, Switzerland. This article is an open access article distributed under the terms and conditions of the Creative Commons Attribution (CC BY) license (https:/ / creativecommons.org/licenses/by/ $4.0 /)$. ductal adenocarcinoma (mPDAC). In this randomized controlled phase I clinical trial, 18 patients with mPDAC pretreated with chemotherapy will be enrolled in one of three study arms: A (control): nivolumab monotherapy; B: percutaneous IRE of the primary tumor followed by nivolumab; or C: intratumoral injection of IMO-2125 followed by percutaneous IRE of the primary tumor and nivolumab. Assessments include contrast enhanced computed tomography (ceCT), ${ }^{18} \mathrm{~F}-\mathrm{FDG}$ and ${ }^{18}$ F-BMS-986192 (PD-L1) positron emission tomography (PET)-CT, biopsies of the primary tumor and metastases, peripheral blood samples, and quality of life and pain questionnaires. There is no curative treatment option for patients with mPDAC, and palliative chemotherapy regimens only moderately improve survival. Consequently, there is an urgent need for innovative and radically different treatment approaches. Should electroimmunotherapy establish an effective and durable anti-tumor response, it may ultimately improve PDAC's dismal prognosis.

Keywords: irreversible electroporation (IRE); nivolumab; IMO-2125; CpG-ODN; metastatic pancreatic cancer; PDAC; checkpoint inhibition; toll-like receptor ligand; PET-C; ablation; immunotherapy

\section{Introduction}

Pancreatic ductal adenocarcinoma (PDAC) is one of the most aggressive forms of cancer, with a 5-year overall survival (OS) rate of only 8\% [1]. About 30\% of newly diagnosed patients present with unresectable locally advanced pancreatic cancer (LAPC) and, despite the introduction of new and more effective chemotherapeutic regimens, responses remain temporary and result in a median OS of 12-14 months [2-4]. Several local treatment strategies have been developed that aim to improve this dismal prognosis [5]. Among them is irreversible electroporation (IRE), a non-thermal needle guided ablation technique that utilizes high-voltage electrical pulses to permanently destabilize the phospholipid bilayer of the tumor cell membrane, enforcing apoptotic and delayed necrotic cell death [6,7]. IRE destroys all cells within the ablation zone but preserves extracellular collagenous matrix structures and allows for the cellular regeneration of inlaying both the blood and lymphatic vessels, making it an attractive local treatment option for LAPC [8]. Clinical efficacy studies for the treatment of LAPC [9] revealed the technique to be of additive value to chemotherapy by improving the OS from diagnosis ranging from 15.3 to 27.0 months [5,10-21].

\subsection{Metastatic Disease}

However, more than $50 \%$ of PDAC patients present with metastatic PDAC (mPDAC), leaving only palliative chemotherapy as a treatment option. With the introduction of FOLFIRINOX (5- fluorouracil, leucovorin, irinotecan, oxaliplatin) in 2012, the prognosis of these patients advanced significantly. Within a trial setting, the median overall survival (OS) improved from 6.8 to 11.1 months [22]. Real-world registry data from the Dutch Cancer Registration (NKR-IKNL) reflected this prognostic improvement but also revealed an attenuated reality with a median OS of 6.4 months in mPDAC patients, including patients unfit for FOLFIRINOX that received $\geq 1$ cycle of chemotherapy [23].

\subsection{Immune Escape}

PDAC has a low mutational burden, resulting in a limited amount of neo-antigens, and its microenvironment is recognized as highly immunosuppressive, allowing the cancer to progress freely [24]. Immune suppression caused by the tumor results from various mechanisms that enable immune cell evasion and exclusion from the tumor microenvironment. Immune evasion is established through the downregulation of antigen presenting pathways (such as MHC-I) by tumor cells, the upregulation of inhibitory immune checkpoint proteins, the restriction of dendritic cell (DC) maturation, and increased apoptotic resistance, thus limiting the release of tumor antigens and immunogenic potential $[25,26]$. Furthermore, the priming of tumor-specific effector $\mathrm{T}$ cells is hampered by active immune suppression through suppressive regulatory T cells (Tregs) and myeloid-derived suppres- 
sor cells (MDSC) in the tumor microenvironment [27-29]. Collectively, these mechanisms can explain PDAC's limited response to immunotherapy [30].

\subsection{Anenestic Effects}

Over the past few years, the interventional oncology community has expanded its research focus from focal cytoreduction to the wider systemic influences that local tumor therapy can produce [31]. The widely used term "abscopal" refers to a visual biological or anatomical response that is distant from the treated site, and is historically connoted with radiotherapy [32]. Thus, in this study protocol, we use the terms "enestic" (response in targeted lesion) and "anenestic" (response in non-targeted lesion) to indicate the local and systemic effects after (intratumoral) treatment, as proposed by the European Society for Medical Oncology (ESMO) [33].

\subsection{Pre-Clinical Evidence IRE Induced Immune Modulation}

It is proposed that focal ablation can enhance antigen presentation, provoke inflammation, and reduce tumor-induced immune suppression [34]. Here within, ablation may represent a means to turn PDAC from an immunologically "cold" tumor into a "hot", immuno-permissive one. Although all ablative modalities may theoretically invoke this mechanism, IRE might possess superior immune potentiating abilities in terms of protein release and T cell activation compared to cryo- or heat ablation [35,36]. Additionally, IRE preserves the larger blood vessels, allowing antigen presenting cells to infiltrate the lesion and transport apoptotic antibodies back to the draining lymph nodes, after which tumor antigen specific $\mathrm{T}$ cell activation is induced $[37,38]$.

\subsection{Clinical Evidence IRE Induced Immune Modulation}

Clinical immune monitoring studies of IRE in pancreatic cancer revealed that highvoltage electrical pulses are able to transiently alleviate tumor-induced immune suppression by decreasing the frequency of circulating Tregs $[39,40]$. This allowed for the simultaneous expansion of activated tumor antigen specific effector T cells, as evidenced by the isolated upregulation of programmed death-1 (PD-1) expression and increased or de novo Wilms Tumor-1 specific responses. The magnitude of the latter effects has been correlated with improved OS [39,40].

\subsection{Pro-Oncogenic Effects}

Similar to the anenestic effects, clinical evidence for pro-oncogenic effects following ablation likewise exists and has been linked to a higher rate of local progression and distant tumor spread in different types of cancer [31]. The exact physiological working mechanism of the immunogenic effects of IRE is not yet fully understood. Therefore, potential pro-oncogenic effects should be taken into consideration. However, based on previous clinical trials in LAPC, pro-oncogenic effects from IRE ablation in PANFIRE-III are deemed unlikely $[19,41]$.

\subsection{Synergy with Immunotherapy}

Although the IRE induced immune response is temporary, it may provide a clinical window of opportunity for potentiation with local or systemic immune enhancing drugs. This treatment combination is termed electroimmunotherapy [42]. PD-1 checkpoint inhibition with nivolumab (Bristol-Meyers Squibb, New York, NY, USA) could release the brakes of the IRE induced effector T cell response to synergistically strengthen the efficacy of both therapies and ultimately establish a durable memory $\mathrm{T}$ cell response [43]. Furthermore, there is increasing evidence that the endogenous immune status prior to treatment, influences the outcome of chemo-, radio-, and ablative therapies. High rates of tumor-infiltrating lymphocytes (TILs) and type 1 interferon (IFN) response signatures are

linked to higher clinical response rates and represent favorable prognostic factors [44-48]. Such optimal immune priming may be achieved by the peri-ablative administration of 
IMO-2125 (Idera pharmaceuticals, Exton, PA, USA), a CpG (cytosine-phosphate-guanine) type $\mathrm{B}$ oligodeoxynucleotide (CpG-B ODNs) functioning as a synthetic toll-like receptor 9 ligand (TLR9-L) that stimulates DCs [49]. Type 1 IFNs released by properly stimulated plasmacytoid DCs activate tumor infiltrating effector T cells and natural killer (NK) cells while recruiting and activating a myeloid DC subset with superior cross-priming abilities, i.e., $\mathrm{CDC} 1[46,47,50]$. These $\mathrm{CDC} 1 \mathrm{~s}$ can prime a new generation of tumor antigen-specific effector $\mathrm{T}$ cells in the draining lymph nodes and may provide the push needed to kick-start a more durable IRE-induced immune response as well as provide improved responsiveness to the immune checkpoint blockade. See Figure 1 for an illustration of electroimmunotherapy as performed in PANFIRE-III.

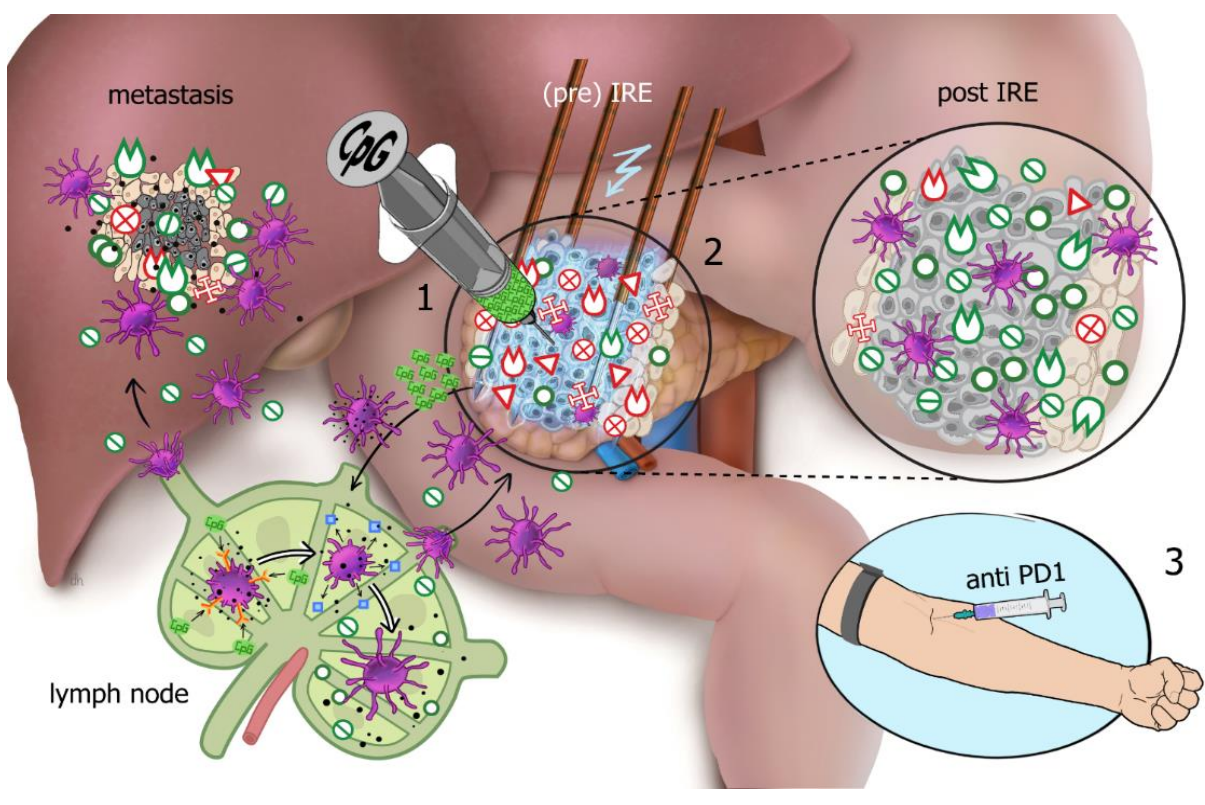

Immune permissive

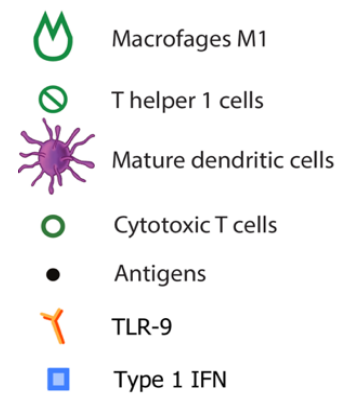

Immune suppressive

$\begin{array}{ll}\Delta & \text { Tregulatory cells } \\ \triangle & \text { Macrofages M2 } \\ \otimes & \text { Thelper } 2 \text { cells } \\ & \text { Suppressive cytokines }\end{array}$

Figure 1. Electroimmunotherapy. Illustrated is the proposed working mechanism of electroimmunotherapy and the three separate treatment stages to achieve synergistic immune modulation as performed in PANFIRE-III study arm C. The primary pancreatic tumor maintains an immunosuppressive microenvironment with the presence of regulatory T cells (Tregs), M2 Macrophages, T helper 2 cells, and suppressive cytokines (red icons), while the effector T cells (T helper 1 cells and cytotoxic T cells) are downregulated. Stage (1): Priming of the tumor microenvironment. CpG (cytosine-phosphate-guanine) type B oligodeoxynucleotide (CpG-B ODN) is injected into the primary tumor and diffuses to the primary tumor-draining lymph nodes where it binds to toll-like receptor 9 (orange receptor) on plasmacytoid dendritic cells (DCs), which mature and release type-1 IFN, which in turn can activate lymph node-resident conventional DCs (cDCs), causing these to mature (purple cells). Effective DC maturation results in their improved ability for tumor antigen uptake and presentation and stimulates type-1 IFN release (blue icons), resulting in the activation of cytotoxic- and helper T cells (green icons). Stage (2): Ablative antigen release and downregulation of tumor induced immune suppression. Irreversible electroporation (IRE) of the primary pancreatic tumor causes massive cell death resulting in antigen release (black dots). Antigens are taken up by DCs and transported back to the lymph nodes for $\mathrm{T}$ cell cross priming to result in adaptive tumor specific $\mathrm{T}$ cell responses (green icons). As IRE reduces the tumor mass, it reduces the secretion of immunosuppressive cytokines and consequently reduces numbers of circulating suppressive immune cell subsets (red icons). The tumor microenvironment shifts from immune suppressive (pre-IRE, red icons) to immune permissive (post-IRE, green icons). Stage (3): Enhancing the induced effector T cell response by intra venous injection of the anti-PD-1 monoclonal antibody (mAb). PD-L1 on the cancer cell surface binds to PD-1 on the T cell surface, inhibiting immune cell activity. Anti-PD-1 mAb (PD-1 checkpoint inhibitor) binds to the PD-1 receptors on the T cells, thereby blocking the receipt of inhibitory signals via PD-L1 and allowing the T cells to uninhibitedly attack the tumor cells (not illustrated). NB: new insights suggest that the PD-1 blockade can also release co-stimulatory signaling in T cells through CD28, leading to increased priming in tumor-draining lymph nodes. Thus, the combination of all three treatment modalities (IRE, CpG, Anti-PD-1) may work synergistically and together may alter the tumor microenvironment to induce a systemic immune response and ultimately cause an "anenestic" effect in distant metastatic lesions (illustrated in the liver). (Reprinted with permission of Geboers et al. [51].) 


\subsection{Hypothesis}

We hypothesize that combining IRE, which reduces immune suppression and stimulates a tumor-specific immune response, with PD-1 checkpoint inhibition using nivolumab and preceded by effective DC priming through intra-tumoral injection of IMO-2125 might establish in vivo immunization and durable treatment results in mPDAC patients.

\section{Materials and Methods}

\subsection{Objectives}

The primary objective of this study is to assess the safety of combining IRE + systemic nivolumab \pm intratumoral IMO-2125 in mPDAC patients with at least stable disease after pretreatment with FOLFIRINOX.

The secondary objective aims to assess the (biological) efficacy of IRE + systemic nivolumab \pm intratumoral IMO-2125 compared to nivolumab monotherapy in terms of local (enestic) or systemic (anenestic) anti-tumor responses, survival, and quality of life.

\subsection{Design}

The PANFIRE III trial is an investigator initiated, prospective, randomized controlled phase I trial performed in the Amsterdam University Medical Centers under the aegis of the national multidisciplinary Dutch Pancreatic Cancer Group (DPCG). The trial is registered at ClinicalTrials.gov under number NCT04612530. A total of 18 patients will be included and will divided over 3 arms. See Figure 2.

- $\quad$ Arm A (control arm): intravenous administration of $240 \mathrm{mg}$ nivolumab every 2 weeks for the first 3 doses followed by intravenous administration of $480 \mathrm{mg}$ every 4 weeks until disease progression.

- Arm B: percutaneous CT-guided (partial) IRE of the primary pancreatic tumor. After 2 weeks, this will be followed by the intravenous administration of $240 \mathrm{mg}$ nivolumab every 2 weeks for 2 doses followed by intravenous administration of 480 mg every 4 weeks until disease progression.

- Arm C: single intratumoral (i.t.) injection of $8 \mathrm{mg}$ IMO-2125, which will be followed by percutaneous CT-guided (partial) IRE of the primary pancreatic tumor after one week. A $240 \mathrm{mg}$ dose of nivolumab is administered intravenously every 2 weeks for 2 doses, which will begin two weeks after IRE, followed by the intravenous administration of $480 \mathrm{mg}$ every 4 weeks until disease progression.

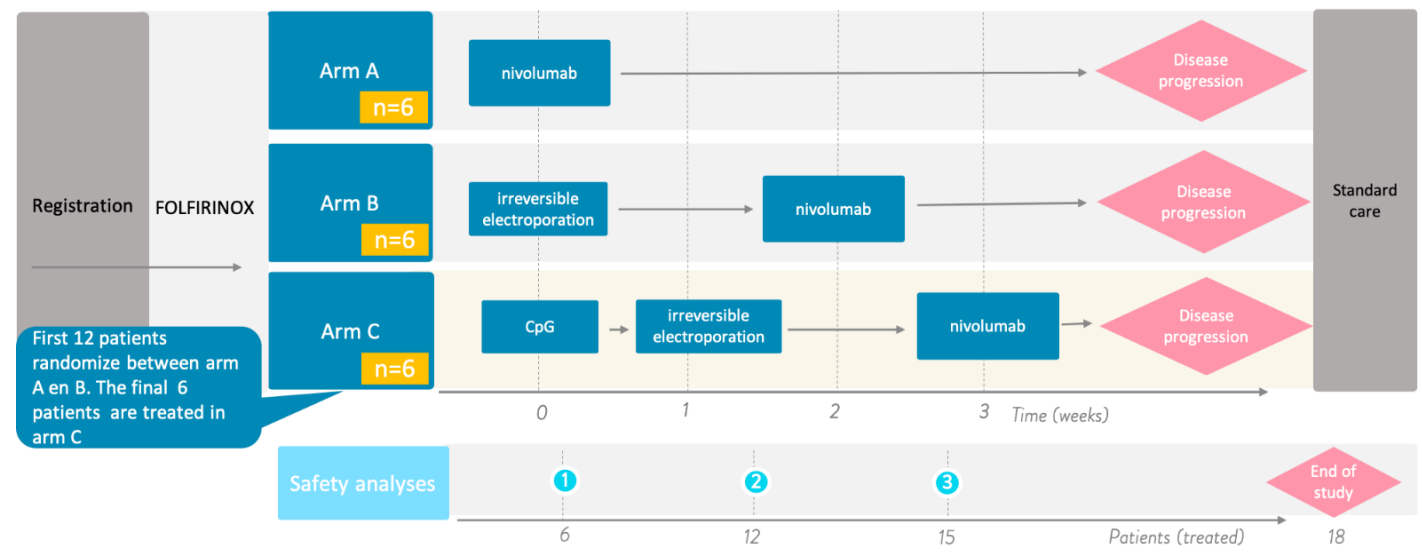

Figure 2. PANFIRE III treatment schedule. All patients require pretreatment with a minimum of 8 cycles of FOLFIRINOX, with at least stable disease, prior to PANFIRE III inclusion. The first 12 patients will be randomized to treatment arm A or B. Arm C will open for the last 6 patients upon the validation of the interim safety analyses. These safety analyses will be performed after the treatment of 6,12, and 15 patients. Arm A: nivolumab monotherapy. Arm B: irreversible electroporation succeeded by intravenous administration of nivolumab. Arm C: priming with intratumoral injection of CpG (IMO-2125), followed by irreversible electroporation after 1 week. This is succeeded by intravenous administration of nivolumab two weeks later. In all treatment arms, nivolumab will be administered until unequivocal disease progression. 


\subsection{Eligibility Criteria}

To be eligible, adult patients require radiologically and histologically proven MPDAC (AJCC stage IV). A maximum of 5 unequivocal metastases of $\geq 1 \mathrm{~cm}$ at the time of inclusion (i.e., after pretreatment with FOLFIRINOX) are allowed. Patients should have at least stable disease (according to RECIST version 5.0) after a minimum of 8 courses of FOLFIRINOX and must be in good clinical condition (WHO 0-2). A minimum of a 4-week interval between the final cycle of chemotherapy and start of the study-related treatment is required. The in- and exclusion criteria are summarized in Table 1. Prior to inclusion, all patients will be discussed in a multidisciplinary hepatopancreaticobilliary (HPB) tumor board consisting of a hepatogastroenterologist, hepatobiliary surgeon, medical oncologist, radiation oncologist, and abdominal and interventional radiologist. Decision on PANFIRE-III trial participation will be at their discretion. All participants will provide written informed consent.

Table 1. In- and exclusion criteria PANFIRE-III.

\begin{tabular}{|c|c|}
\hline Inclusion & Exclusion \\
\hline $\begin{array}{l}\text { Radiologically and histopathologically } \\
\text { proven stage IV pancreatic cancer } \\
\text { (according to the AJCC staging system } \\
\text { for pancreatic cancer [52]). }\end{array}$ & Brain metastases. \\
\hline $\begin{array}{l}\text { Max. } 5 \text { unequivocal metastases } \geq 1 \mathrm{~cm} \\
\text { at the time of inclusion (i.e., after } \\
\text { FOLFIRINOX). }\end{array}$ & Active epilepsy (last convulsion $<5$ years). \\
\hline & History of cardiac disease: \\
\hline Primary tumor is in situ. & $\begin{array}{l}\text { - } \quad \text { Congestive heart failure }>\text { NYHA Class } 2 . \\
\text { - } \quad \text { Active coronary artery disease (defined as myocardial infarction within } \\
6 \text { months prior to screening). } \\
\text { - } \\
\text { Ventricular cardiac arrhythmias requiring anti-arrhythmic therapy or } \\
\text { pacemaker (beta-blockers for antihypertensive regimen are permitted; } \\
\text { atrial fibrillation is not contra-indicated). }\end{array}$ \\
\hline $\begin{array}{l}\text { A minimum of } 8 \text { cycles of FOLFIRINOX } \\
\text { chemotherapy is required before study } \\
\text { inclusion, with at least stable disease } \\
\text { according to RECIST. }\end{array}$ & Known hypersensitivity to any oligodeoxynucleotides. \\
\hline Age $\geq 18$ years & $\begin{array}{l}\text { Compromised liver function defined as warning signs of portal hypertension, } \\
\text { INR }>1,5 \text { without use of anticoagulants, bilirubin }>\times 1.5 \text { Upper limit of } \\
\text { normal range }(\mathrm{ULN}) \text { ASAT }>3.0 \times \text { ULN, ALAT }>3.0 \times \text { ULN. }\end{array}$ \\
\hline $\begin{array}{l}\text { World Health Organization }(\mathrm{WHO}) \text { scale } \\
\text { performance status } 0-2 \text {. }\end{array}$ & $\begin{array}{l}\text { Compromised kidney function defined as eGFR }<30 \mathrm{~mL} / \mathrm{min} \text { (using the } \\
\text { Cockcroft Gault formula). }\end{array}$ \\
\hline \multirow[t]{11}{*}{$\begin{array}{l}\text { Adequate bile drainage in case of biliary } \\
\text { obstruction. }\end{array}$} & $\begin{array}{l}\text { Active autoimmune disease requiring disease-modifying therapy at the time } \\
\text { of screening, i.e., }>10 \mathrm{mg} \text { prednisolone per day or equivalent to this regimen. }\end{array}$ \\
\hline & $\begin{array}{c}\text { Uncontrolled hypertension. Blood pressure must be } \leq 160 / 95 \mathrm{mmHg} \text { at the } \\
\text { time of screening on a stable antihypertensive regimen. }\end{array}$ \\
\hline & Uncontrolled infections (>grade $2 \mathrm{NCI}-\mathrm{CTC}$ version 3.0) requiring antibiotics. \\
\hline & Immunotherapy prior to the procedure for the treatment of cancer. \\
\hline & Previous surgical therapy for pancreatic cancer. \\
\hline & $\begin{array}{l}\text { Second primary malignancy with median } 5 \text {-year OS }<90 \% \text {. This excludes } \\
\text { adequately treated cancers such as non-melanoma skin cancer, in situ } \\
\text { carcinoma of the cervix uteri, superficial bladder cancer, or other malignancies } \\
\text { that have been previously treated without signs of recurrence. }\end{array}$ \\
\hline & Allergy to contrast agent. \\
\hline & Allergy to PET tracers 18F-FDG and 18F-BMS-986192. \\
\hline & Any implanted stimulation device. \\
\hline & $\begin{array}{l}\text { Portal vein or VMS stenosis }>70 \% \text {, or any arterial stenosis (superior } \\
\text { mesenteric artery, celiac artery, common hepatic artery) }>70 \% \text { unless } \\
\text { effectively stented. }\end{array}$ \\
\hline & $\begin{array}{l}\text { Any condition that is unstable or that could jeopardize the safety of the subject } \\
\text { and their compliance in the study. }\end{array}$ \\
\hline
\end{tabular}

\subsection{Interventions}

\subsubsection{Percutaneous CT-Guided IRE}

A total of 12 patients ( $n=6$ in arm B and $n=6$ in arm C) will receive IRE treatment of the primary tumor under general anesthesia induced with propofol, sufentanil, and 
rocuronium and maintained with propofol and remifentanil. Antibiotic prophylaxis will be administered within one hour prior to the procedure (Cefuroxim $1500 \mathrm{mg}$ i.v. and Metronidazole $500 \mathrm{mg}$ i.v.). A pre-procedural 4-F straight flush catheter (Cordis Corporation, Bridgewater, NJ, USA) flush catheter will be introduced via the right common femoral artery in the abdominal aorta up to a supraceliac level for per-procedural transcatheter CT arteriography [41]. All ablations will be performed percutaneously using ceCT guidance and will be employed using the NanoKnife system under ECG-gating (AccuSync model 72; AngioDynamics, Latham, New York, USA). A defibrillator will be present at all times. A pre-procedural catheter guided ceCT scan (unenhanced, arterial (7 s), and early portal venous phase (22 s)) will be performed for tumor staging confirmation, exact tumor size measurement, and electrode planning. Depending on tumor size, 2-6 needle electrodes will be placed in the bulky part of the tumor in a parallel fashion while aiming at an inter-electrode distance of $20 \mathrm{~mm}( \pm 2 \mathrm{~mm})$ with at least a $5 \mathrm{~mm}$ margin from adjacent critical structures [53]. The generator-based tumor free margin will be set at $5 \mathrm{~mm}$, and the working length of the electrodes will be set at $15 \mathrm{~mm}$. Ablations may be intentionally incomplete, aiming for antigen release rather than optimal cytoreduction and emphasizing patient safety. The ablation protocol consists of 10 test pulses of $1500 \mathrm{~V} / \mathrm{cm}$ and $90 \mu \mathrm{s}$ per electrode pair followed by a sequential pulsing scheme of 90 additional pulses per electrode pair. The voltage per centimeter setting can be adjusted in $10 \%$ steps in case of a pending under- or overcurrent ( $<20 \mathrm{~A}$ or $>45 \mathrm{~A}$, respectively). Immediately after IRE, a control transcatheter arteriography abdominal CT scan will be made to evaluate possible early complications. Additional periprocedural interventions to enhance safety are allowed such as placement of biliary endoprosthesis, percutaneous transhepatic cholangiography drainage, or arterial/portal venous stenting in case of an impending IRE-induced occlusion.

\subsubsection{Anti-PD-1 Monoclonal Antibody (mAb) (Nivolumab)}

All patients $(N=18)$ will initially receive $240 \mathrm{mg}$ nivolumab (dissolved in $250 \mathrm{~mL}$ $\mathrm{NaCl} 0.9 \%$ ) administered intravenously every 2 weeks-3 doses in arm A and 2 doses in arms B and C-followed by $480 \mathrm{mg}$ nivolumab (dissolved in $500 \mathrm{~mL} \mathrm{NaCl} \mathrm{0.9 \% )} \mathrm{admin-}$ istered intravenously every 4 weeks. Nivolumab will be administered until unequivocal disease progression. The infusion time will be 30-60 min. Blood will be drawn prior to every treatment cycle, verifying hematological and endocrinological values, tumor marker CA19.9, electrolytes, albumin, and kidney and liver function. See Table 2.

\subsubsection{CpG Oligodeoxynucleotide (IMO-2125)}

All patients in arm $C(n=6)$ will receive a single intratumoral injection with $8 \mathrm{mg}$ of IMO-2125 dissolved in $1 \mathrm{~mL} \mathrm{NaCl} \mathrm{0.9 \% .} \mathrm{Injection} \mathrm{will} \mathrm{be} \mathrm{administered} \mathrm{in} \mathrm{a} \mathrm{daycare} \mathrm{setting}$ under local anesthesia and will be performed percutaneously using CT and/or ultrasound guidance. IMO-2125 solution will be injected with a 21-gauge stainless steel disposable needle with side holes indicated for the infusion and aspiration of fluids (ProFusion ${ }^{\mathrm{TM}}$, Cook, Bloomington, IN, USA).

\subsection{Outcome Measures}

The primary objective (safety) will be assessed by recording adverse events (AEs) and serious adverse events (SAEs) directly associated with each treatment arm occurring up to 90 days after any of the interventions according to the Common Terminology Criteria of Adverse Events (CTCAE) v5.0 [54].

The secondary objective ([biological] efficacy) will be assessed using biochemical responses (tumor marker CA19.9), immunological responses (flow cytometry, histopathology/immunohistochemistry (IHC), proteomics), radiological responses (contrast-enhanced computed tomography (ceCT)), nuclear radiological responses $\left({ }^{18} \mathrm{~F}\right.$-fluorodeoxyglucose (FDG), and ${ }^{18}$ F-BMS-986192 (Programmed Death- Ligand 1 (PD-L1)) positron emissioncomputed tomography (PET) CT imaging) [55]. Furthermore, quality of life and pain questionnaires, overall survival (OS), and progression-free survival (PFS) will be recorded. 
Inherent to the phase I trial design and small study sample, OS and PFS are specifically evaluated subordinate to and in relation to the previously noted outcome measures.

Table 2. Required blood tests prior to Nivolumab administration PANFIRE-III.

\begin{tabular}{|c|c|c|}
\hline Lab Test & $\begin{array}{l}\text { Prior to First Cycle of } \\
\text { Nivolumab }\end{array}$ & $\begin{array}{c}\text { Prior to Consecutive Cycles } \\
\text { of Nivolumab }\end{array}$ \\
\hline Full blood: & $\begin{array}{l}\text { hemoglobin/leukocytes and } \\
\text { differentiation/thrombocytes }\end{array}$ & $\begin{array}{l}\text { hemoglobin/leukocytes and } \\
\text { differentiation/thrombocytes }\end{array}$ \\
\hline Electrolytes: & $\begin{array}{l}\text { natrium/potassium/calcium/ } \\
\text { magnesium/phosphate }\end{array}$ & natrium/potassium \\
\hline Liver function: & $\begin{array}{c}\text { albumin/glucose/lipase/bilir } \\
\text { ubin/Alkaline } \\
\text { phosphatase/ } \gamma \text {-glutamine } \\
\text { transferase/aspartate- } \\
\text { aminotransferase/alanine- } \\
\text { aminotransferase/lactate- } \\
\text { dehydrogenase }\end{array}$ & $\begin{array}{l}\text { albumin/glucose/lipase/ } \\
\text { bilirubin/Alkaline } \\
\text { phosphatase/ } \gamma \text {-glutamine } \\
\text { transferase/aspartate- } \\
\text { aminotransferase/alanine- } \\
\text { aminotransferase/lactate- } \\
\text { dehydrogenase }\end{array}$ \\
\hline Kidney function: & creatinine/urea & creatinine \\
\hline Thyroid function: & $\begin{array}{l}\text { thyroid stimulating } \\
\text { hormone/thyroxin }\end{array}$ & $\begin{array}{l}\text { thyroid stimulating } \\
\text { hormone/thyroxin }\end{array}$ \\
\hline Acute phase proteins: & c-reactive protein & c-reactive protein \\
\hline Hormones: & $\begin{array}{c}\text { cortisol/luteinizing } \\
\text { hormone/follicle stimulating } \\
\text { hormone/adrenocorticotropic } \\
\text { hormone }\end{array}$ & \\
\hline Tumor markers: & CA19.9 & \\
\hline
\end{tabular}

\subsection{Data Collection and Analysis}

\subsubsection{Interim Safety Analysis}

To ensure safety and to monitor toxicity of the electroimmunotherapeutic treatment combinations a $3+3$ step up design will be implemented. The study will be split into 4 phases, separated by interim safety analyses: phase 1 (inclusion 1-6), phase 2 (inclusion 7-12), phase 3 (inclusion 13-15), and phase 4 (inclusion 16-18). Randomized inclusion will start in arms A and B (phases 1 and 2) at the same time to minimize selection bias and to secure optimal qualitative immunological analyses of the added value of IRE to nivolumab in mPDAC. Inclusion in arm C (phases 3 and 4) will start after the finalization of the confirmed safety of arms A and B after the second interim analysis. Interim safety analyses will be assessed by the following stopping rules based on recommendations of the clinical trial design task force of the National Institutes of Health Investigational Drug Steering Committee [56]: if $>50 \%$ of patients within one study arm per study phase develop a grade 5 drug- or IRE-related SAE (i.e., death) within 30 days after treatment and/or if $>50 \%$ of all included patients overall develop a grade 4 drug- or IRE-related SAE within 30 days after treatment, the study will be terminated.

\subsubsection{Survival}

Overall survival (OS) is defined as the date of the first study-related treatment $(\mathrm{T}=0)$ until the date of death from any cause. Progression-free survival (PFS) is defined as the time from the first study-related treatment until the date of unequivocal disease progression according to iRECIST [57] and PERCIST [58] criteria.

\subsubsection{Blood and Tissue}

Systemic and local immune responses will be assessed by sampling venous blood and primary and metastatic tumor tissue in the same session. Samples will be collected at 3 different time points: baseline, 2 ( $\operatorname{arm~A,~B)~or~} 3$ ( $\operatorname{arm~C)}$ weeks, and 5 ( $\operatorname{arm~A,~B)~or~}$ 
6 (arm C) weeks after the first study-related treatment. In arm C, extra blood samples will be collected 1 week after study start to assess the systemic immune response after initial intratumoral injection with CpG. Blood will be examined by flow cytometry for changes in frequency and the activation/proliferation status of several suppressive and permissive immune-cell subsets (memory/effector $\mathrm{CD}^{+}$and $\mathrm{CD} 8^{+} \mathrm{T}$ cells, Tregs, B cells, DCs, NK cells and MDSCs). Tissue will be analyzed using flow cytometry (tumor-infiltrating lymphocytes (memory / effector $\mathrm{CD}^{+}{ }^{+}$and $\mathrm{CD} 8^{+} \mathrm{T}$ cells, Tregs) and NK cells), histopathology/IHC (microsatellite instability, tumor-infiltrating lymphocytes, myeloid infiltration (M2 macrophages, DCs) and tumor markers), and proteomic analysis. Biochemical responses will be assessed by the evaluation of tumor marker CA19.9 in venous blood drawn at baseline and prior to every nivolumab treatment cycle. See Figure 3 for the timing of the study assessments.

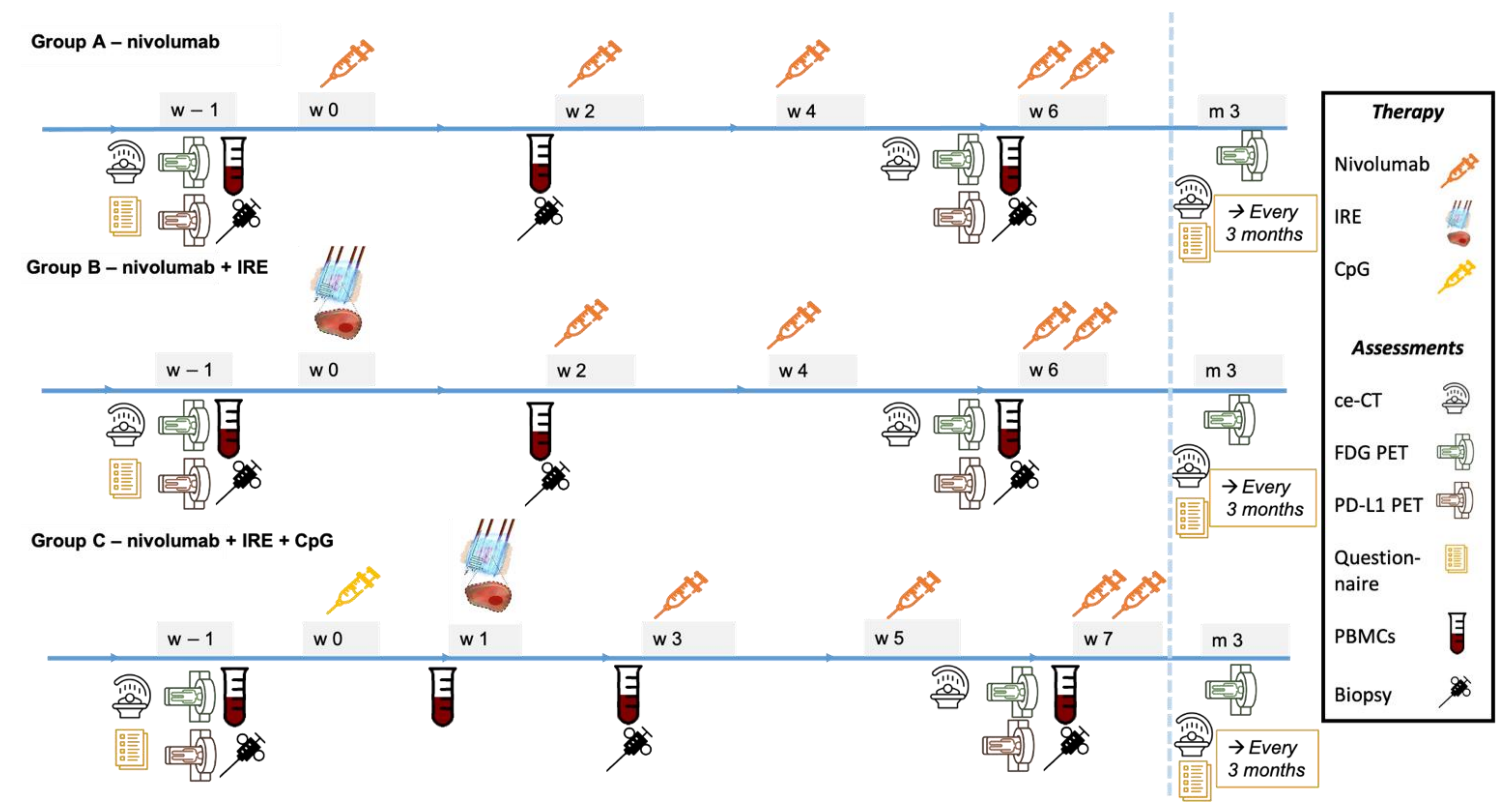

Figure 3. PANFIRE III specified treatment schedule and study assessments per study arm. Arm A: nivolumab monotherapy; intravenous administration of $240 \mathrm{mg}$ nivolumab every 2 weeks for 3 doses followed by intravenous administration of $480 \mathrm{mg}$ nivolumab every 4 weeks. Assessments: ceCT (baseline, 5 weeks, and after every 3 months), FDG and PD-L1-PET (baseline and 5 weeks), blood and biopsy sampling (baseline, 2 weeks (prior to second nivolumab administration) and 5 weeks (prior to fourth nivolumab administration)), and QOL questionnaires (baseline and every 3 months). Arm B: irreversible electroporation succeeded by intravenous administration of $240 \mathrm{mg}$ nivolumab every 2 weeks for 2 doses followed by intravenous administration of $480 \mathrm{mg}$ nivolumab every 4 weeks. Assessments: ceCT (baseline, 5 weeks, and after every 3 months), FDG and PD-L1-PET (baseline and 6 weeks), blood and biopsy sampling (baseline, 2 weeks (prior to second nivolumab administration) and 5 weeks (prior to fourth nivolumab administration)), and QOL questionnaires (baseline and every 3 months). Arm C: priming with intratumoral injection of IMO-2125 after 1 week followed by irreversible electroporation. This is succeeded 2 weeks later by intravenous administration of 240 mg nivolumab every 2 weeks for 2 doses followed by intravenous administration of $480 \mathrm{mg}$ nivolumab every 4 weeks. Assessments: ceCT (baseline, 6 weeks, and after every 3 months), FDG and PD-L1-PET (baseline and 6 weeks), blood and biopsy sampling (baseline, 1 week, 3 weeks (prior to first nivolumab administration), and 6 weeks (prior to third nivolumab administration)), and QOL questionnaires (baseline and every 3 months). In all treatment arms, nivolumab will be administered until unequivocal disease progression. W: week, M: month, IRE: irreversible electroporation, ceCT: contrast enhanced computed tomography, PET: positron emission tomography, FDG: fluorodeoxyglucose, PD-L1 PET: programmed death-ligand 1. Double syringe nivolumab at 6 (arm A/B) and 7 (arm C) weeks illustrates change of nivolumab dosing from $240 \mathrm{mg}$ fortnightly to $480 \mathrm{mg}$ monthly.

\subsubsection{Imaging}

Radiological responses will be assessed by ceCT (SOMATOM Sensation or Drive, Siemens AG, München, Germany), and nuclear radiological responses will be assessed 
by ${ }^{18}$ F-FDG PET-CT, and ${ }^{18}$ F-BMS-986192 (Bristol Meyer Squibb) PET-CT (Philips Gemini TF PET-CT system, Philips Medical Systems, Cleveland, OH, USA) and performed at 3 different time points: baseline, 2 ( $\operatorname{arm~A,~B)~or~} 3$ (arm C) weeks, and 5 ( $\operatorname{arm~A,~B)~or~}$ $6(\operatorname{arm~C})$ weeks after treatment start. A third ceCT and ${ }^{18}$ F-FDG PET-CT will be performed 3 months after the start of treatment in all study arms.

CeCT imaging (abdomen and thorax) is conducted according to EANM guidelines to assess viable tumor lesions, enestic tumor response (primary lesion), and anenestic tumor response (metastatic lesion) (see discussion) [59]. Treatment response to ceCT is assessed using the immune response evaluation criteria in solid tumors (iRECIST) [57,60]. iRECIST utilizes an intermediary progressive state known as unconfirmed progressive disease (iUPD), in which a radiological increase in the sum of the target lesions $(>20 \%$; longest diameter; axial plane), unequivocal progression of existing non-target lesions, or the appearance of one or more new lesions are identified. The unconfirmed progressive disease is only confirmed (iCPD) if at the subsequent imaging timepoint, the target sum has further increased $(\geq 5 \mathrm{~mm}$ ) or if there is additional unequivocal progression of non-target lesions and/or the appearance of new lesions (sum $\geq 5 \mathrm{~mm}$ ). However, if the subsequent imaging after iUPD reveals stable disease (SD), partial response (PR), or complete response (CR) (compared with baseline), the iUPD status is reset to the newly acquired status.

Changes in ${ }^{18} \mathrm{~F}-\mathrm{FDG}$ and ${ }^{18} \mathrm{~F}-\mathrm{BMS}-986192$ uptake in tumor lesions and organs of interest (as measured both visually and semi-quantitatively by means of different standardized uptake values (SUVs)) from baseline to early and late treatment will be investigated and correlated with radiological response and blood and tissue analyses. Whole body PET (vertex to mid-thigh) will start $60 \mathrm{~min}$ after tracer injection followed by a ceCT for attenuation correction and the anatomical correlation of ${ }^{18} \mathrm{~F}-\mathrm{FDG}$ and ${ }^{18} \mathrm{~F}-\mathrm{BMS}-986192$ PET. To prevent remaining ${ }^{18} \mathrm{~F}$ signal at the time the second scan, a minimum delay of 10 half-lives $(19 \mathrm{~h})$ will be ensured. In order to validate the usage of the derived image, SUVs of the ${ }^{18} \mathrm{~F}$-BMS-986192 tracer venous blood sampling will be performed at 5, 10, 20, 30, 40 and $55( \pm 5)$ minutes post injection.

\subsubsection{Questionnaires}

Pain and quality of life will be assessed using validated visual analog score (VAS) questionnaires and Quality of Life Questionnaires (QLQ) at baseline and every threemonths as part of the PACAP-trial (NCT03513705) [61].

\subsection{Follow-Up}

Patient follow-up after the first 3 months will consist of blood sampling prior to every consecutive nivolumab administration (see Table 2), ceCT imaging every 3 months, and quality of life and pain questionnaires every 3 months. Study medication will be stopped after 12 months or when unequivocal disease progression occurs. The trial will end twelve months after the inclusion of the final patient.

\subsection{Data Collection and Handling}

Data will be collected by the study coordinators and will be treated confidentially and anonymously. A subject identification code will be used to link the data to the subject. The study coordinators safeguard the key to the identification code. The handling of personal data complies with the Dutch Personal Data Protection Act. See Figure 4 for overview of all analysis modalities.

\subsection{Sample Size Calculation and Statistical Considerations}

In this phase I trial, a sample size of 6 patients per treatment arm and the $3+3$ step-up design are based on establishing early safety data. No power analysis was performed as efficacy is not the primary study objective. 


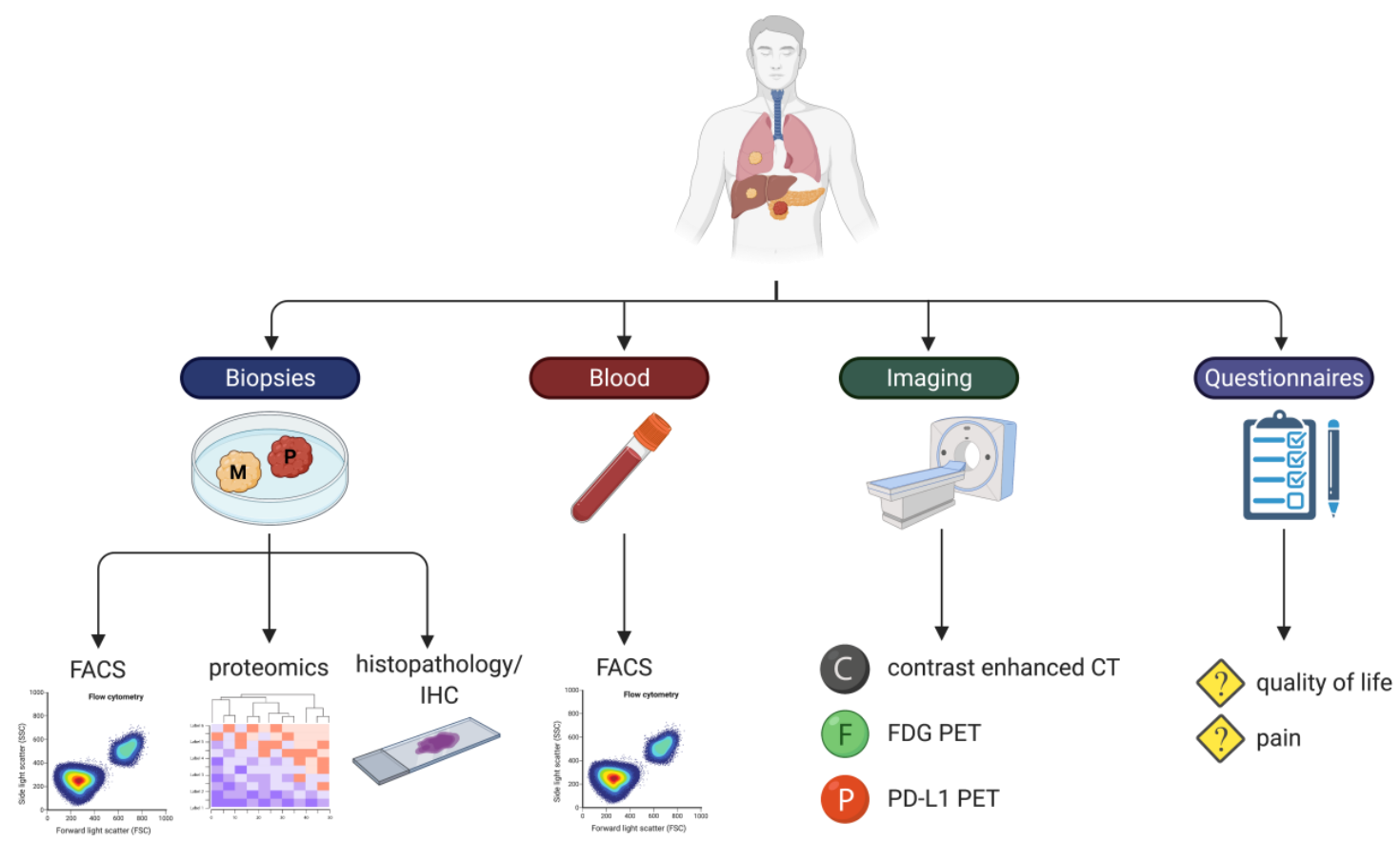

Figure 4. Data collection and analyses per patient in PANFIRE-III. Biopsies from primary (P) and metastatic (M) tissue will be analyzed using flow cytometry, histopathology/immunohistochemistry (IHC), and proteomics. Blood samples will be analyzed using flow cytometry. Imaging will be performed by ceCT, FDG $\left({ }^{18}\right.$ F-FDG) PET-CT, and PD-L1 ( ${ }^{18}$ F-BMS-986192) PET-CT. Pain scores and quality of life scores will be evaluated by validated questionnaires.

\section{Discussion}

\subsection{Preclinical Evidence of Synergy}

While the exact mechanism of action underlying systemic effects of IRE is not fully understood, it most likely involves the release of antigens and the activity of DCs, as they regulate tolerance versus immunity, depending on their maturation state $[62,63]$. Exposure to sufficient quantities of antigens and maturation signals, i.e., damage associated molecular patterns (DAMPs), leaves DCs capable of upregulating their T cell stimulatory function. Ablation results in massive tumor cell death [37] and can provoke an immune cascade of tumor antigen and DAMP release, DC activation, and tumor antigen uptake followed by migration to the lymph nodes, where effector $\mathrm{T}$ cell cross-priming can take place [64-66]. Activated T cells may subsequently home to loco-regional and distant sites to eliminate (micro-)metastases producing an anenestic effect [67]. Research in an immunocompetent PDAC murine model that leveraged this ablation-induced immune response by combining IRE with anti-PD-1 mAbs provided encouraging outcomes in terms of immune activation, tumor regression, and improved survival [43]. Furthermore, it was observed that priming the tumor micro-environment with the injection of $\mathrm{CpG}, 7$ days prior to ablation, could further enhance effective synergistic tumor control in an epithelial cancer mouse model [68].

\subsection{Clinical Evidence of Synergy}

The first clinical trials combining IRE with immunotherapy, such as adoptive allogenic natural killer cell therapy and PD-1 checkpoint inhibition, were actively pursued in end stage pancreatic cancer patients and the combinations were proven to be safe with promising preliminary efficacy results $[69,70]$.

\subsection{Timing of Study Interventions}

The specific timing and sequence of IMO-2125, IRE, and Nivolumab administration in PANFIRE-III are based on observations of immune cell kinetics in previous studies. Simultaneous Treg downregulation and tumor specific CD4 and CD8 T cell expansion with 
increased PD-1 expression peak 14 days after ablation in IRE treated PDAC patients [40]. Hence, the onset of Nivolumab administration 14 days after IRE ablation in arm B and C to potentially release the brakes on this effector $\mathrm{T}$ cell response. Earlier discussed preclinical findings on DC priming are in accordance with clinical findings of optimally increased DC frequency and maturation status, in both the circulation and sentinel lymph nodes, 7 days after CpG administration [71,72]. Consequently, IMO-2125 is intratumorally administered 7 days prior to IRE ablation aiming to secure optimal DC priming at the time of ablative antigen release.

The addition of immunotherapeutic agents to FOLFIRINOX is also proposed to strengthen and synergistically increase anti-tumor effects [73]. Systemic chemotherapy itself can promote the release of tumor antigens and may activate anti-cancer immunity to enhance tumor growth suppression $[74,75]$. In this regard, pre-treatment with FOLFIRINOX in this trial might add to the improved tumor sensitivity to nivolumab in all treatment arms. PANFIRE-III aims to gain new insights into the potentially synergistic pathways of both ablation and chemotherapy in combination with immunotherapeutic agents in mPDAC.

\subsection{Immune Response}

This study's flow cytometric, histopathologic/IHC, and proteomic analyses of primary and metastatic biopsy samples will provide unique insights into the different mechanisms that drive the local and systemic immune response to achieve the desired enestic and anenestic effects in mPDAC. The flow cytometric analyses of blood samples will allow comparison of the development of systemic innate and adaptive immune responses after each treatment and over time. Assessments of the post treatment immune responses are specifically timed for optimal comparison between the treatment arms. Blood and tissue are sampled 2 (arm A and B) or 3 weeks ( $\operatorname{arm} C$ ) and 5 (arm A and B) or 6 weeks (arm C) after start of the treatment for the assessment of the innate immune response to each individual treatment (arm A: nivolumab, arm B: IRE, arm C: CpG + IRE) and the adaptive immune response to each individual treatment in combination with Nivolumab, respectively. To optimally compare the immune effects induced by IRE to the addition of CpG and/or Nivolumab, identical timing between IRE ablation, blood and tissue sampling, and imaging in arm B and C were given precedence over the uniform timing of data collection. Hence, sampling in $\operatorname{arm} C$ is deferred by 1 week. See Figure 3 for the timing of blood and tissue sampling.

If electroimmunotherapy proves safe, potential radiological, immunological, or biochemical responses generated in this study will provide new information that will be valuable for the optimization of combination treatment strategies for mPDAC.

\subsection{Imaging}

The PANFIRE-III trial primarily focuses on the typical ceCT and ${ }^{18} \mathrm{~F}-\mathrm{FDG}$ PET-CT imaging characteristics of tumor tissue over time and during follow-up. Although the performance of ${ }^{18} \mathrm{~F}$-FDG PET in the follow-up of PDAC after treatment with immunotherapeutic drugs is unexplored, a meta-analysis of the use of ${ }^{18}$ F-FDG PET in combination with ceCT for detection of recurrent disease reported a reasonable diagnostic accuracy with pooled estimates for sensitivity and specificity of $95 \%$ and $81 \%$, respectively [76]. Additionally, preclinical evidence supports the potential of ${ }^{18}$ F-FDG PET to monitor checkpoint inhibitors associated metabolic changes in lymphoid organs [77].

However, there is a need to improve PDAC detection, prognosis prediction, and treatment response evaluation. Conventional imaging techniques such as ceCT, MRI or EUS do not always offer a reliable differentiation between PDAC and benign conditions or between viable tumor and necrotic tissue after neo-adjuvant chemotherapy, nor do they provide insight into the immune status of the tumor microenvironment and the lymphoid organs. Additionally, the emerging prescription of immunotherapies warrants new and accurate diagnostic techniques for response evaluation. PET imaging with novel tracers 
such as the PD-L1 targeting ${ }^{18}$ F-BMS-986192 tracer [78] could offer an innovative approach for these hurdles. Imaging with ${ }^{18}$ F-BMS-986192 was previously studied in non-small cell lung cancer patients prior to treatment with anti-PD-1 mAbs and was proven to be feasible and safe [55]. It was found that patients responding to treatment with anti-PD$1 \mathrm{mAbs}$ experienced higher ${ }^{18} \mathrm{~F}-\mathrm{BMS}-986192$ uptake than non-responders. No clinical PET studies with PD-L1 tracers have been performed in pancreatic cancer patients yet. Hence, the incorporated explorative ${ }^{18} \mathrm{~F}$-BMS-986192 tracer study is primarily used for tracer validation in metastatic pancreatic cancer patients, as it will generate qualitative and quantitative information about the tracer's uptake in the tumor and lymphoid organs. Additionally, it might provide new insights in innate and adaptive immune dynamics following each treatment combination. Indeed, type-1 IFN release by pDC upon CpG binding may induce PD-L1 expression in both tumor and immune cells; additionally, T cells that are recruited to and are activated in the tumor microenvironment may induce PD-L1 expression through IFN $\gamma$ release. It should be noted that the amount of delivered ${ }^{18} \mathrm{~F}$-BMS986192 is in the nanomolar quantity and is far below the dose required for pharmacological effects.

\section{Conclusions}

Electroimmunotherapy through a combination of IRE with local and systemic immunotherapeutic agents may provide efficient in vivo immunization against pancreatic cancer. PANFIRE-III aims to assess the safety and (biological) efficacy of combination therapy with IRE, nivolumab, and IMO-2125 in patients with mPDAC that have been effectively pre-treated with FOLFIRINOX.

The study treatment might allow the immune system to initiate systemic tumor degradation and protection against further tumor growth and spread. When proven safe and clinically reproducible, future research should be pursued to optimize the dosage and timing of drug administration, IRE pulse delivery settings, and choice of immunotherapeutic agents. If electroimmunotherapy can truly be used to trigger a systemic anti-tumor effect and can incite a durable response in patients with mPDAC, IRE may provide the missing link between local and systemic treatment in pancreatic cancer.

Author Contributions: Conceptualization, B.G., H.J.v.d.V., J.W.W., H.J.S., T.D.d.G., and M.R.M.; methodology, B.G., F.E.F.T., A.H.R., J.J.J.d.V., C.W.M.-v.d.H.v.O., H.J.v.d.V., J.W.W., H.J.S., T.D.d.G., and M.R.M.; investigation, B.G., F.E.F.T., J.E.E.P., E.A.C.S., J.B., J.J.J.d.V., D.E.O.-L., C.W.M.-v.d.H.v.O., H.J.v.d.V., J.W.W., H.J.S., T.D.d.G., and M.R.M.; resources, B.G., C.W.M.-v.d.H.v.O., J.W.W., H.J.S., T.D.d.G., and M.R.M.; data curation, F.E.F.T., E.A.C.S., J.B., T.D.d.G., and M.R.M.; writing-original draft preparation, B.G.; writing-review and editing, F.E.F.T., A.H.R., J.E.E.P., E.A.C.S., J.B., R.S.P., S.N., M.D., M.P.v.d.T., J.J.J.d.V., D.E.O.-L., C.W.M.-v.d.H.v.O., H.J.v.d.V., J.W.W., H.J.S., T.D.d.G., and M.R.M.; visualization, B.G., F.E.F.T., and J.E.E.P.; supervision, T.D.d.G. and M.R.M.; project administration, B.G., F.E.F.T., and E.A.C.S.; funding acquisition, H.J.S., T.D.d.G., and M.R.M. All authors have read and agreed to the published version of the manuscript.

Funding: This research is funded by Cancer Center Amsterdam grant number CCA2018-5-44 and Adessium Foundation grant number CCA2019-5-56.

Institutional Review Board Statement: The study was conducted according to the guidelines of the Declaration of Helsinki and approved by the Medical Ethics Committee of Amsterdam UMC (location VUmc) (2020.231-NL73415.029.20, date of approval: 24-08-2020).

Informed Consent Statement: Informed consent is obtained from all subjects involved in the study.

Data Availability Statement: Not applicable.

Acknowledgments: Figure 1 was created by Dana Hamers Scientific Arts and illustration was funded by AngioDynamics. Figure 4 was created with BioRender.com (accessed on 28 June 2021). Guus A.M.S. van Dongen (department of Radiology and Nuclear medicine, Amsterdam University Medical Centers, Cancer Center Amsterdam, the Netherlands) significantly contributed to the acquisition of funding and PET tracer side-study design. the Dutch Pancreatic Cancer Group is Available online: https:/ / dpcg.nl. 
Conflicts of Interest: M.R.M. is a paid consultant for Angiodynamics; H.J.v.d.V. is the CSO of LAVA Therapeutics; T.D.d.G. has a research grant from Idera Pharmaceuticals and sits on the advisory boards of DCPrime and LAVA Therapeutics. Idera Pharmaceuticals provided IMO-2125 (tilsotolimod) for use in this study. Bristol-Myers Squibb provided Nivolumab (Opdivo ${ }^{\circledR}$ ) for use in this study. AngioDynamics provided IRE-needle electrodes for use in this study. None of the companies donating resources had a role in the design of the study; in the collection, analyses or interpretation of data; in the writing of the manuscript, or in the decision to publish the results.

\section{References}

1. Siegel, R.L.; Miller, K.D.; Fedewa, S.A.; Ahnen, D.J.; Meester, R.G.S.; Barzi, A.; Jemal, A. Colorectal cancer statistics. CA Cancer J. Clin. 2017, 67, 177-193. [CrossRef] [PubMed]

2. Rombouts, S.J.; Walma, M.S.; Vogel, J.A.; van Rijssen, L.B.; Wilmink, J.W.; Mohammad, N.H.; van Santvoort, H.C.; Molenaar, I.Q.; Besselink, M.G. Systematic Review of Resection Rates and Clinical Outcomes After FOLFIRINOX-Based Treatment in Patients with Locally Advanced Pancreatic Cancer. Ann. Surg. Oncol. 2016, 23, 4352-4360. [CrossRef]

3. Suker, M.; Beumer, B.R.; Sadot, E.; Marthey, L.; Faris, J.E.; Mellon, E.A.; El-Rayes, B.F.; Wang-Gillam, A.; Lacy, J.; Hosein, P.J.; et al. FOLFIRINOX for locally advanced pancreatic cancer: A systematic review and patient-level meta-analysis. Lancet Oncol. 2016, 17, 801-810. [CrossRef]

4. Vincent, A.; Herman, J.; Schulick, R.; Hruban, R.H.; Goggins, M. Pancreatic cancer. Lancet 2011, 378, 607-620. [CrossRef]

5. Ruarus, A.; Vroomen, L.; Puijk, R.; Scheffer, H.; Meijerink, M. Locally Advanced Pancreatic Cancer: A Review of Local Ablative Therapies. Cancers 2018, 10, 16. [CrossRef]

6. Mercadal, B.; Beitel-White, N.; Aycock, K.N.; Castellví, Q.; Davalos, R.V.; Ivorra, A. Dynamics of Cell Death After Conventional IRE and H-FIRE Treatments. Ann. Biomed. Eng. 2020, 48, 1451-1462. [CrossRef] [PubMed]

7. Brock, R.M.; Beitel-White, N.; Davalos, R.V.; Allen, I.C. Starting a Fire Without Flame: The Induction of Cell Death and Inflammation in Electroporation-Based Tumor Ablation Strategies. Front. Oncol. 2020, 10, 1235. [CrossRef]

8. Vogel, J.A.; Vroomen, L.G.P.H.; Srimathveeravalli, G. The Effect of Irreversible Electroporation on Blood Vessels, Bile Ducts, Urinary Tract, Intestines, and Nerves, in Irreversible Electroporation in Clinical Practice; Meijerink, M.R., Scheffer, H.J., Narayanan, G., Eds.; Springer International Publishing: Cham, Switzerland, 2018; pp. 81-94.

9. Ruarus, A.H.; Vroomen, L.; Puijk, R.S.; Scheffer, H.J.; Zonderhuis, B.M.; Kazemier, G.; van den Tol, M.P.; Berger, F.H.; Meijerink, M.R. Irreversible Electroporation in Hepatopancreaticobiliary Tumours. Can. Assoc. Radiol. J. 2018, 69, 38-50. [CrossRef] [PubMed]

10. Martin, R.C.; Philips, P.; Ellis, S.; Hayes, D.; Bagla, S. Irreversible electroporation of unresectable soft tissue tumors with vascular invasion: Effective palliation. BMC Cancer 2014, 14, 540. [CrossRef]

11. Belfiore, G.; Belfiore, M.P.; Reginelli, A.; Capasso, R.; Romano, F.; Ianniello, G.P.; Cappabianca, S.; Brunese, L. Concurrent chemotherapy alone versus irreversible electroporation followed by chemotherapy on survival in patients with locally advanced pancreatic cancer. Med. Oncol. 2017, 34, 38. [CrossRef] [PubMed]

12. Coelen, R.J.S.; Vogel, J.A.; Vroomen, L.; Roos, E.; Busch, O.R.C.; van Delden, O.M.; Delft, F.V.; Heger, M.; van Hooft, J.E.; Kazemier, G.; et al. Ablation with irreversible electroporation in patients with advanced perihilar cholangiocarcinoma (ALPACA): A multicentre phase I/II feasibility study protocol. BMJ Open 2017, 7, e015810. [CrossRef] [PubMed]

13. Leen, E.; Picard, J.; Stebbing, J.; Abel, M.; Dhillon, T.; Wasan, H. Percutaneous irreversible electroporation with systemic treatment for locally advanced pancreatic adenocarcinoma. J. Gastrointest. Oncol. 2018, 9, 275-281. [CrossRef] [PubMed]

14. Paiella, S.; Butturini, G.; Frigerio, I.; Salvia, R.; Armatura, G.; Bacchion, M.; Fontana, M.; D'Onofrio, M.; Martone, E.; Bassi, C. Safety and feasibility of Irreversible Electroporation (IRE) in patients with locally advanced pancreatic cancer: Results of a prospective study. Dig. Surg. 2015, 32, 90-97. [CrossRef]

15. Martin, R.C., 2nd; Kwon, D.; Chalikonda, S.; Sellers, M.; Kotz, E.; Scoggins, C.; McMasters, K.M.; Watkins, K. Treatment of 200 locally advanced (stage III) pancreatic adenocarcinoma patients with irreversible electroporation: Safety and efficacy. Ann. Surg. 2015, 262, 486-494. [CrossRef]

16. Narayanan, G.; Bhatia, S.; Echenique, A.; Suthar, R.; Barbery, K.; Yrizarry, J. Vessel patency post irreversible electroporation. Cardiovasc. Intervent. Radiol. 2014, 37, 1523-1529. [CrossRef]

17. Mansson, C.; Bergenfeldt, M.; Brahmstaedt, R.; Karlson, B.M.; Nygren, P.; Nilsson, A. Safety and preliminary efficacy of ultrasound-guided percutaneous irreversible electroporation for treatment of localized pancreatic cancer. Anticancer Res. 2014, 34, 289-293.

18. Kluger, M.D.; Epelboym, I.; Schrope, B.A.; Mahendraraj, K.; Hecht, E.M.; Susman, J.; Weintraub, J.L.; Chabot, J.A. Single-Institution Experience with Irreversible Electroporation for T4 Pancreatic Cancer: First 50 Patients. Ann. Surg. Oncol. 2016, 23, 1736-1743. [CrossRef]

19. Scheffer, H.J.; Vroomen, L.G.; de Jong, M.C.; Melenhorst, M.C.; Zonderhuis, B.M.; Daams, F.; Vogel, J.A.; Besselink, M.G.; van Kuijk, C.; Witvliet, J.; et al. Ablation of Locally Advanced Pancreatic Cancer with Percutaneous Irreversible Electroporation: Results of the Phase I/II PANFIRE Study. Radiology 2017, 282, 585-597. [CrossRef] [PubMed] 
20. Van Veldhuisen, E.; Vroomen, L.G.; Ruarus, A.H.; Derksen, T.C.; Busch, O.R.; de Jong, M.C.; Kazemier, G.; Puijk, R.S.; Sorgedrager, N.S.; Vogel, J.A.; et al. Value of CT-Guided Percutaneous Irreversible Electroporation Added to FOLFIRINOX Chemotherapy in Locally Advanced Pancreatic Cancer: A Post Hoc Comparison. J. Vasc. Interv. Radiol. 2020, 31, 1600-1608. [CrossRef]

21. He, C.; Wang, J.; Zhang, Y.; Lin, X.; Li, S. Irreversible electroporation after induction chemotherapy versus chemotherapy alone for patients with locally advanced pancreatic cancer: A propensity score matching analysis. Pancreatology 2020, 20, 477-484. [CrossRef] [PubMed]

22. Conroy, T.; Desseigne, F.; Ychou, M.; Bouche, O.; Guimbaud, R.; Becouarn, Y.; Adenis, A.; Raoul, J.L.; Gourgou-Bourgade, S.; de la Fouchardiere, C.; et al. FOLFIRINOX versus gemcitabine for metastatic pancreatic cancer. N. Engl. J. Med. 2011, 364, 1817-1825. [CrossRef] [PubMed]

23. Nederlandse Kankerregistratie (NKR), IKNL. Available online: iknl.nl/nkr-cijfers (accessed on 28 March 2019).

24. Das, M.; Zhou, X.; Liu, Y.; Das, A.; Vincent, B.G.; Li, J.; Liu, R.; Huang, L. Tumor neoantigen heterogeneity impacts bystander immune inhibition of pancreatic cancer growth. Transl. Oncol. 2020, 13, 100856. [CrossRef] [PubMed]

25. Sideras, K.; Braat, H.; Kwekkeboom, J.; van Eijck, C.H.; Peppelenbosch, M.P.; Sleijfer, S.; Bruno, M. Role of the immune system in pancreatic cancer progression and immune modulating treatment strategies. Cancer Treat. Rev. 2014, 40, 513-522. [CrossRef]

26. Bowers, J.; Bailey, S.; Rubinstein, M.; Paulos, C.; Camp, E.R. Genomics meets immunity in pancreatic cancer: Current research and future directions for pancreatic adenocarcinoma immunotherapy. Oncol. Rev. 2019, 13, 102-113. [CrossRef]

27. Li, M.; Bharadwaj, U.; Zhang, R.; Zhang, S.; Mu, H.; Fisher, W.E.; Brunicardi, F.C.; Chen, C.; Yao, Q. Mesothelin is a malignant factor and therapeutic vaccine target for pancreatic cancer. Mol. Cancer Ther. 2008, 7, 286-296. [CrossRef]

28. Hiraoka, N.; Onozato, K.; Kosuge, T.; Hirohashi, S. Prevalence of FOXP3+ regulatory T cells increases during the progression of pancreatic ductal adenocarcinoma and its premalignant lesions. Clin. Cancer Res. 2006, 12, 5423-5434. [CrossRef]

29. Gabitass, R.F.; Annels, N.E.; Stocken, D.D.; Pandha, H.A.; Middleton, G.W. Elevated myeloid-derived suppressor cells in pancreatic, esophageal and gastric cancer are an independent prognostic factor and are associated with significant elevation of the Th2 cytokine interleukin-13. Cancer Immunol. Immunother. 2011, 60, 1419-1430. [CrossRef] [PubMed]

30. Schizas, D.; Charalampakis, N.; Kole, C.; Economopoulou, P.; Koustas, E.; Gkotsis, E.; Ziogas, D.; Psyrri, A.; Karamouzis, M.V. Immunotherapy for pancreatic cancer: A 2020 update. Cancer Treat. Rev. 2020, 86, 102016. [CrossRef]

31. Erinjeri, J.P.; Fine, G.C.; Adema, G.J.; Ahmed, M.; Chapiro, J.; den Brok, M.; Duran, R.; Hunt, S.J.; Johnson, D.T.; Ricke, J.; et al. Immunotherapy and the Interventional Oncologist: Challenges and Opportunities-A Society of Interventional Oncology White Paper. Radiology 2019, 292, 25-34. [CrossRef]

32. Mole, R.H. Whole Body Irradiation-Radiobiology or Medicine? Br. J. Radiol. 1953, 26, 234-241. [CrossRef]

33. Marabelle, A.; Andtbacka, R.; Harrington, K.; Melero, I.; Leidner, R.; de Baere, T.; Robert, C.; Ascierto, P.A.; Baurain, J.F.; Imperiale, M.; et al. Starting the fight in the tumor: Expert recommendations for the development of human intratumoral immunotherapy (HIT-IT). Ann. Oncol. 2018, 29, 2163-2174. [CrossRef]

34. Van den Bijgaart, R.J.E.; Schuurmans, F.; Fütterer, J.J.; Verheij, M.; Cornelissen, L.A.M.; Adema, G.J. Immune Modulation Plus Tumor Ablation: Adjuvants and Antibodies to Prime and Boost Anti-Tumor Immunity In Situ. Front. Immunol. 2021, 12, 617365. [CrossRef]

35. Shao, Q.; O’Flanagan, S.; Lam, T.; Roy, P.; Pelaez, F.; Burbach, B.J.; Azarin, S.M.; Shimizu, Y.; Bischof, J.C. Engineering T cell response to cancer antigens by choice of focal therapeutic conditions. Int. J. Hyperth. 2019, 36, 130-138. [CrossRef]

36. White, S.B.; Zhang, Z.; Chen, J.; Gogineni, V.R.; Larson, A.C. Early Immunologic Response of Irreversible Electroporation versus Cryoablation in a Rodent Model of Pancreatic Cancer. J. Vasc. Interv. Radiol. 2018, 29, 1764-1769. [CrossRef] [PubMed]

37. Rubinsky, B.; Onik, G.; Mikus, P. Irreversible electroporation: A new ablation modality—clinical implications. Technol. Cancer Res. Treat. 2007, 6, 37-48. [CrossRef] [PubMed]

38. Jose, A.; Sobrevals, L.; Ivorra, A.; Fillat, C. Irreversible electroporation shows efficacy against pancreatic carcinoma without systemic toxicity in mouse models. Cancer Lett. 2012, 317, 16-23. [CrossRef] [PubMed]

39. Pandit, H.; Hong, Y.K.; Li, Y.; Rostas, J.; Pulliam, Z.; Li, S.P.; Martin, R.C.G. Evaluating the Regulatory Immunomodulation Effect of Irreversible Electroporation (IRE) in Pancreatic Adenocarcinoma. Ann. Surg. Oncol. 2019, 26, 800-806. [CrossRef]

40. Scheffer, H.J.; Stam, A.G.M.; Geboers, B.; Vroomen, L.; Ruarus, A.; de Bruijn, B.; van den Tol, M.P.; Kazemier, G.; Meijerink, M.R.; de Gruijl, T.D. Irreversible electroporation of locally advanced pancreatic cancer transiently alleviates immune suppression and creates a window for antitumor T cell activation. Oncoimmunology 2019, 8, 1652532. [CrossRef]

41. Ruarus, A.H.; Vroomen, L.; Geboers, B.; van Veldhuisen, E.; Puijk, R.S.; Nieuwenhuizen, S.; Besselink, M.G.; Zonderhuis, B.M.; Kazemier, G.; de Gruijl, T.D.; et al. Percutaneous Irreversible Electroporation in Locally Advanced and Recurrent Pancreatic Cancer (PANFIRE-2): A Multicenter, Prospective, Single-Arm, Phase II Study. Radiology 2020, 294, 212-220. [CrossRef]

42. Geboers, B.; Scheffer, H.J.; Graybill, P.M.; Ruarus, A.H.; Nieuwenhuizen, S.; Puijk, R.S.; van den Tol, P.M.; Davalos, R.V.; Rubinsky, B.; de Gruijl, T.D.; et al. High-Voltage Electrical Pulses in Oncology: Irreversible Electroporation, Electrochemotherapy, Gene Electrotransfer, Electrofusion, and Electroimmunotherapy. Radiology 2020, 295, 254-272. [CrossRef]

43. Zhao, J.; Wen, X.; Tian, L.; Li, T.; Xu, C.; Wen, X.; Melancon, M.P.; Gupta, S.; Shen, B.; Peng, W.; et al. Irreversible electroporation reverses resistance to immune checkpoint blockade in pancreatic cancer. Nat. Commun. 2019, 10, 899. [CrossRef] [PubMed]

44. Oji, Y.; Nakamori, S.; Fujikawa, M.; Nakatsuka, S.; Yokota, A.; Tatsumi, N.; Abeno, S.; Ikeba, A.; Takashima, S.; Tsujie, M.; et al. Overexpression of the Wilms' tumor gene WT1 in pancreatic ductal adenocarcinoma. Cancer Sci. 2004, 95, 583-587. [CrossRef] [PubMed] 
45. Ulloa-Montoya, F.; Louahed, J.; Dizier, B.; Gruselle, O.; Spiessens, B.; Lehmann, F.F.; Suciu, S.; Kruit, W.H.; Eggermont, A.M.; Vansteenkiste, J.; et al. Predictive gene signature in MAGE-A3 antigen-specific cancer immunotherapy. J. Clin. Oncol. 2013, 31, 2388-2395. [CrossRef]

46. Fuertes, M.B.; Kacha, A.K.; Kline, J.; Woo, S.R.; Kranz, D.M.; Murphy, K.M.; Gajewski, T.F. Host type I IFN signals are required for antitumor $\mathrm{CD}^{+} \mathrm{T}$ cell responses through CD8 $\alpha^{+}$dendritic cells. J. Exp. Med. 2011, 208, 2005-2016. [CrossRef]

47. Fuertes, M.B.; Woo, S.R.; Burnett, B.; Fu, Y.X.; Gajewski, T.F. Type I interferon response and innate immune sensing of cancer. Trends Immunol. 2013, 34, 67-73. [CrossRef] [PubMed]

48. Zitvogel, L.; Galluzzi, L.; Kepp, O.; Smyth, M.J.; Kroemer, G. Type I interferons in anticancer immunity. Nat. Rev. Immunol. 2015, 15, 405-414. [CrossRef]

49. Krieg, A.M. CpG still rocks! Update on an accidental drug. Nucleic Acid. Ther. 2012, 22, 77-89. [CrossRef]

50. Woo, S.R.; Corrales, L.; Gajewski, T.F. The STING pathway and the T cell-inflamed tumor microenvironment. Trends Immunol. 2015, 36, 250-256. [CrossRef]

51. Geboers, B.; Ruarus, A.H.; Nieuwenhuizen, S.; Puijk, R.S.; Scheffer, H.J.; de Gruijl, T.D.; Meijerink, M.R. Needle-guided ablation of locally advanced pancreatic cancer: Cytoreduction or immunomodulation by in vivo vaccination? Chin. Clin. Oncol. 2019, 8, 61. [CrossRef]

52. Kakar, S.; Pawlik, T.M.; Allen, P.J. Exocrine Pancreas. Pancreatic adenocarcinoma. In AJCC Cancer Staging Manual, 8th ed.; Amin, M.B., Ed.; Springer: New York, NY, USA, 2016.

53. Timmer, F.E.F.; Geboers, B.; Ruarus, A.H.; Schouten, E.A.C.; Nieuwenhuizen, S.; Puijk, R.S.; de Vries, J.J.J.; Meijerink, M.R.; Scheffer, H.J. Irreversible Electroporation for Locally Advanced Pancreatic Cancer. Tech. Vasc. Interv. Radiol. 2020, $23,100675$. [CrossRef]

54. U.S. Department of Health and Human Services National Institutes of Health; NCI. Common Terminology Criteria for Adverse Events Version 5.0. Available online: https:/ / evs.nci.nih.gov/ftp1/CTCAE/About.html (accessed on 6 December 2019).

55. Niemeijer, A.N.; Leung, D.; Huisman, M.C.; Bahce, I.; Hoekstra, O.S.; van Dongen, G.A.M.S.; Boellaard, R.; Du, S.; Hayes, W.; Smith, R.; et al. Whole body PD-1 and PD-L1 positron emission tomography in patients with non-small-cell lung cancer. Nat. Commun. 2018, 9, 4664. [CrossRef]

56. Ivy, S.P.; Siu, L.L.; Garrett-Mayer, E.; Rubinstein, L. Approaches to Phase 1 Clinical Trial Design Focused on Safety, Efficiency, and Selected Patient Populations: A Report from the Clinical Trial Design Task Force of the National Cancer Institute Investigational Drug Steering Committee. Clin. Cancer Res. 2010, 16, 1726. [CrossRef] [PubMed]

57. Seymour, L.; Bogaerts, J.; Perrone, A.; Ford, R.; Schwartz, L.H.; Mandrekar, S.; Lin, N.U.; Litière, S.; Dancey, J.; Chen, A.; et al. iRECIST: Guidelines for response criteria for use in trials testing immunotherapeutics. Lancet Oncol. 2017, 18, e143-e152. [CrossRef]

58. Wahl, R.L.; Jacene, H.; Kasamon, Y.; Lodge, M.A. From RECIST to PERCIST: Evolving Considerations for PET response criteria in solid tumors. J. Nucl. Med. 2009, 50, 122s-150s. [CrossRef] [PubMed]

59. Boellaard, R.; O’Doherty, M.J.; Weber, W.A.; Mottaghy, F.M.; Lonsdale, M.N.; Stroobants, S.G.; Oyen, W.J.; Kotzerke, J.; Hoekstra, O.S.; Pruim, J.; et al. FDG PET and PET/CT: EANM procedure guidelines for tumour PET imaging: Version 1.0. Eur. J. Nucl. Med. Mol. Imaging 2010, 37, 181-200. [CrossRef] [PubMed]

60. Watanabe, H.; Okada, M.; Kaji, Y.; Satouchi, M.; Sato, Y.; Yamabe, Y.; Onaya, H.; Endo, M.; Sone, M.; Arai, Y. New response evaluation criteria in solid tumours-revised RECIST guideline (version 1.1). Gan To Kagaku Ryoho 2009, 36, $2495-2501$.

61. Mackay, T.M.; Smits, F.J.; Latenstein, A.E.J.; Bogte, A.; Bonsing, B.A.; Bos, H.; Bosscha, K.; Brosens, L.A.A.; Hol, L.; Busch, O.R.C.; et al. Impact of nationwide enhanced implementation of best practices in pancreatic cancer care (PACAP-1): A multicenter stepped-wedge cluster randomized controlled trial. Trials 2020, 21, 334. [CrossRef]

62. Palucka, K.; Banchereau, J. Dendritic-cell-based therapeutic cancer vaccines. Immunity 2013, 39, 38-48. [CrossRef]

63. Garg, A.D.; Romano, E.; Rufo, N.; Agostinis, P. Immunogenic versus tolerogenic phagocytosis during anticancer therapy: Mechanisms and clinical translation. Cell. Death Differ. 2016, 23, 938-951. [CrossRef] [PubMed]

64. den Brok, M.H.; Sutmuller, R.P.; Nierkens, S.; Bennink, E.J.; Frielink, C.; Toonen, L.W.; Boerman, O.C.; Figdor, C.G.; Ruers, T.J.; Adema, G.J. Efficient loading of dendritic cells following cryo and radiofrequency ablation in combination with immune modulation induces anti-tumour immunity. Br. J. Cancer 2006, 95, 896-905. [CrossRef]

65. Shan, C.C.; Shi, L.R.; Ding, M.Q.; Zhu, Y.B.; Li, X.D.; Xu, B.; Jiang, J.T.; Wu, C.P. Cytokine-induced killer cells co-cultured with dendritic cells loaded with the protein lysate produced by radiofrequency ablation induce a specific antitumor response. Oncol. Lett. 2015, 9, 1549-1556. [CrossRef] [PubMed]

66. Lutz, E.; Yeo, C.J.; Lillemoe, K.D.; Biedrzycki, B.; Kobrin, B.; Herman, J.; Sugar, E.; Piantadosi, S.; Cameron, J.L.; Solt, S.; et al. A lethally irradiated allogeneic granulocyte-macrophage colony stimulating factor-secreting tumor vaccine for pancreatic adenocarcinoma. A Phase II trial of safety, efficacy, and immune activation. Ann. Surg. 2011, 253, 328-335.

67. Schumacher, T.N.; Schreiber, R.D. Neoantigens in cancer immunotherapy. Science 2015, 348, 69-74. [CrossRef] [PubMed]

68. Silvestrini, M.T.; Ingham, E.S.; Mahakian, L.M.; Kheirolomoom, A.; Liu, Y.; Fite, B.Z.; Tam, S.M.; Tucci, S.T.; Watson, K.D.; Wong, A.W.; et al. Priming is key to effective incorporation of image-guided thermal ablation into immunotherapy protocols. JCI Insight 2017, 2, e90521. [CrossRef] [PubMed] 
69. Lin, M.; Alnaggar, M.; Liang, S.; Wang, X.; Liang, Y.; Zhang, M.; Chen, J.; Niu, L.; Xu, K. An important discovery on combination of irreversible electroporation and allogeneic natural killer cell immunotherapy for unresectable pancreatic cancer. Oncotarget 2017, 8, 101795-101807. [CrossRef]

70. O'Neill, C.; Hayat, T.; Hamm, J.; Healey, M.; Zheng, Q.; Li, Y.; Martin, R.C.G., 2nd. A phase $1 b$ trial of concurrent immunotherapy and irreversible electroporation in the treatment of locally advanced pancreatic adenocarcinoma. Surgery 2020, 168, 610-616. [CrossRef]

71. Molenkamp, B.G.; van Leeuwen, P.A.; Meijer, S.; Sluijter, B.J.; Wijnands, P.G.; Baars, A.; van den Eertwegh, A.J.; Scheper, R.J.; de Gruijl, T.D. Intradermal CpG-B activates both plasmacytoid and myeloid dendritic cells in the sentinel lymph node of melanoma patients. Clin. Cancer Res. 2007, 13, 2961-2969. [CrossRef]

72. Molenkamp, B.G.; Sluijter, B.J.; van Leeuwen, P.A.; Santegoets, S.J.; Meijer, S.; Wijnands, P.G.; Haanen, J.B.; van den Eertwegh, A.J.; Scheper, R.J.; de Gruijl, T.D. Local administration of PF-3512676 CpG-B instigates tumor-specific CD8+ T-cell reactivity in melanoma patients. Clin. Cancer Res. 2008, 14, 4532-4542. [CrossRef]

73. Smyth, M.J.; Ngiow, S.F.; Ribas, A.; Teng, M.W.L. Combination cancer immunotherapies tailored to the tumour microenvironment. Nat. Rev. Clin. Oncol. 2015, 13, 143. [CrossRef]

74. Zitvogel, L.; Galluzzi, L.; Smyth, M.J.; Kroemer, G. Mechanism of Action of Conventional and Targeted Anticancer Therapies: Reinstating Immunosurveillance. Immunity 2013, 39, 74-88. [CrossRef]

75. Weiss, G.J.; Waypa, J.; Blaydorn, L.; Coats, J.; McGahey, K.; Sangal, A.; Niu, J.; Lynch, C.A.; Farley, J.H.; Khemka, V. A phase Ib study of pembrolizumab plus chemotherapy in patients with advanced cancer (PembroPlus). Br. J. Cancer 2017, 117, 33. [CrossRef] [PubMed]

76. Daamen, L.A.; Groot, V.P.; Goense, L.; Wessels, F.J.; Rinkes, I.H.B.; Intven, M.P.W.; van Santvoort, H.C.; Molenaar, I.Q. The diagnostic performance of CT versus FDG PET-CT for the detection of recurrent pancreatic cancer: A systematic review and meta-analysis. Eur. J. Radiol. 2018, 106, 128-136. [CrossRef] [PubMed]

77. Schwenck, J.; Schörg, B.; Fiz, F.; Sonanini, D.; Forschner, A.; Eigentler, T.; Weide, B.; Martella, M.; Gonzalez-Menendez, I.; Campi, C.; et al. Cancer immunotherapy is accompanied by distinct metabolic patterns in primary and secondary lymphoid organs observed by non-invasive in vivo (18)F-FDG-PET. Theranostics 2020, 10, 925-937. [CrossRef] [PubMed]

78. Huisman, M.C.; Niemeijer, A.L.N.; Windhorst, A.D.; Schuit, R.C.; Leung, D.; Hayes, W.; Poot, A.; Bahce, I.; Radonic, T.; Oprea-Lager, D.E.; et al. Quantification of PD-L1 expression with [(18)F]BMS-986192 PET/CT in patients with advanced stage non-small-cell lung cancer. J. Nucl. Med. 2020, 61, 1455-1460. [CrossRef] 